\title{
A simulation-based evaluation of substation models for network flexibility characterisation in district heating networks
}

Annelies Vandermeulen ${ }^{\mathrm{a}, \mathrm{b}, \mathrm{c}, *}$, Tijs Van Oevelen ${ }^{\mathrm{a}, \mathrm{c}}$, Bram van der Heijde ${ }^{\mathrm{a}, \mathrm{b}, \mathrm{c}}$, Lieve Helsen ${ }^{\mathrm{a}, \mathrm{b}}$

${ }^{a}$ Energy Ville, Thor Park, Poort Genk 8310, 3600 Genk, Belgium

${ }^{b}$ KU Leuven, Department of Mechanical Engineering, Celestijnenlaan 300 box 2421, 3001 Leuven, Belgium

${ }^{c}$ VITO, Boeretang 200, 2400 Mol, Belgium

\section{Abstract}

To aid in the integration of renewable and residual energy sources in the energy system, energy flexibility is required. By charging and discharging energy storage, energy flexibility can be created and heat demand and heat generation can be matched in time. One possible source of energy flexibility is the thermal capacity of the water in district heating network pipes. Effective use of this thermal energy storage requires efficient techniques to determine the available flexibility. The goal of this paper is to assess which substation models are suitable for network flexibility characterisation through simulation. The substation models differ in the assumptions that are made and range from a detailed, non-linear model to a simple, linear model. To analyse the results, we identify different phases occurring during a network flexibility activation. By determining if reduced models are as effective in reproducing

${ }^{*}$ Corresponding author. EnergyVille, Thor Park, Poort Genk 8310, 3600 Genk, Belgium E-mail address: annelies.vandermeulen@energyville.be 
important flexibility characteristics as more detailed and computationally expensive models, network flexibility characterisation can be simplified and sped up. Results show that the network flexibility can be adequately characterised even with very simple models, provided correct assumptions are made.

Keywords: Thermal network, District heating, Energy flexibility, Substation, Simulation, Modelica

\section{List of Symbols}

$\begin{array}{ccl}A & \mathrm{~m}^{2} & \text { Pipe cross section area } \\ c_{\mathrm{p}} & \mathrm{J} /(\mathrm{kg} \mathrm{K}) & \text { Specific heat capacity of water } \\ C & \mathrm{~W} / \mathrm{K} & \text { Heat capacity rate of a heat exchanger } \\ C^{*} & - & \text { Heat capacity ratio of a heat exchanger } \\ E & \mathrm{kWh} & \text { Energy } \\ K & - & \text { Constant indicating heat exchanger size } \\ \dot{m} & \mathrm{~kg} / \mathrm{s} & \text { Mass flow rate } \\ N T U & - & \text { Number of transfer units } \\ t & \mathrm{~s} & \text { Time } \\ T & { }^{\circ} \mathrm{C} & \text { Temperature } \\ \dot{Q} & \mathrm{~kW} & \text { Heat flow } \\ U A & \mathrm{~W} / \mathrm{K} & \text { Heat exchanger conductance } \\ x & \mathrm{~m} & \text { Position along network pipes } \\ \epsilon & - & \text { Heat exchanger effectiveness } \\ \rho & \mathrm{kg} / \mathrm{m}^{3} & \text { Mass density of water }\end{array}$

List of subscripts 


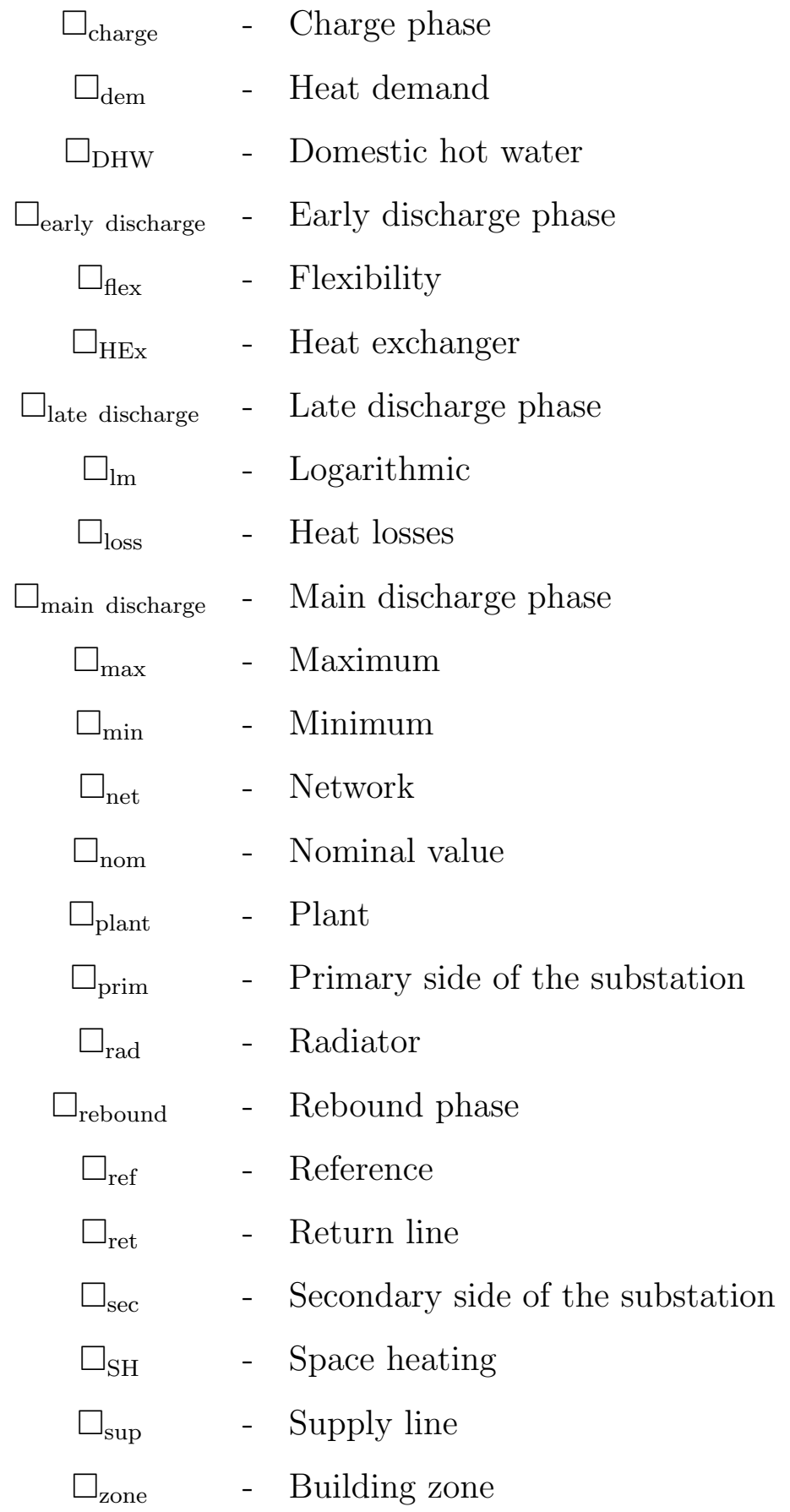




\section{Introduction}

\subsection{Background and motivation}

In the transition towards a sustainable energy system, district heating and cooling (DHC) is considered an important technology by the European Commission [1]. As shown by Paardekooper et al. [2] district heating is a cost-effective solution in the 14 countries of Heat Roadmap Europe [3] to provide at least half of the heat demand and to significantly reduce $\mathrm{CO}_{2}$ emissions. Especially the possibility of integrating residual energy sources, originating from waste incineration and industrial processes, supports the choice for district heating in a sustainable energy system. Furthermore, Lund [4] argued that, in addition to a smart electricity grid, we need smart gas and district heating and cooling (DHC) networks, due to the lower costs of gas storage and thermal energy storage (TES) as compared to electric energy storage.

Energy storage plays an important role in this sustainable energy system by providing energy flexibility. Energy flexibility is defined as the ability to shift the energy injection into or energy extraction from a system in time to bypass system limitations originating from e.g. intermittent renewable and residual energy sources $\left(\mathrm{R}^{2} \mathrm{ES}\right)$ [5]. By using the links between the electrical and district heating (DH) systems, e.g. Combined Heat and Power (CHP) units and heat pumps, energy flexibility can be made possible by TES in DH systems. Possible forms of TES in DH systems are aquifers, pits, storage tanks, building thermal inertia and the thermal capacity of the water in the pipes. As is stated by Frederiksen and Werner [6], the thermal capacity of the

network can be accessed by temporarily increasing the supply temperature. 
The two main advantages of network thermal capacity compared to other forms of TES are 1) its inherent presence in a DH network which avoids extra investment as opposed to dedicated storage tanks. 2) Its ease of access, as compared to the thermal inertia of buildings that are also inherently present in the network. To access the capacity of the building thermal mass, building owners need to cooperate and the buildings need advanced controllers that can be steered towards a common goal. By contrast, a central advanced controller can easily access the network pipe thermal capacity by changing the supply temperature level in the network.

This thermal capacity of a district heating system has been used several times in the literature using different methods and goals. Basciotti et al. [7] assessed the possibility to provide peak shaving with the network thermal capacity in a simulation study and concluded that in their case peak reductions of up to $15 \%$ are possible. Giraud et al. 8 developed an optimal controller to minimise total operational costs of a district heating system using the thermal capacity of the network. They tested this controller in a simulation study and concluded that savings up to $8.3 \%$ are possible. Lesko et al. [9] also developed an optimal controller to maximise CHP production using the network thermal capacity. Li et al. [10] and $\mathrm{Gu}$ et al. [11] in their turn have also devised optimal control problems to integrate $\mathrm{R}^{2} \mathrm{ES}$, again using the thermal network capacity to create flexibility. Pan et al. [12] also studies the integration of $\mathrm{R}^{2} \mathrm{ES}$ but through a simulation study.

Wherever the flexibility is coming from, it needs to be characterised in order to be applied efficiently. Many characterisation techniques already exist, yet most of them are designed for TES in buildings. Some, such as 
Nuytten et al. [13] and Stinner et al. [14], defined indicators such as the average power and energy of the temporary heat load increase/decrease and amount of time during which this change occurs. Others quantify flexibility in terms of the extra cost of shifting energy use in time, e.g. De Coninck and Helsen [15]. Additionally, their work is based on optimisation, i.e. what is the optimal way of using flexibility, while the others are based on simulation. Reynders [16] defined various flexibility characteristics for the thermal inertia of building structures, such as state of charge, storage efficiency and available storage capacity. Furthermore, Reynders et al. [17] presented a review of different quantification techniques for TES in buildings. A more general technique for flexibility quantification, applicable to systems other than building thermal inertia, was proposed by the IEA EBC Annex 67 [18]. This quantification entails the analysis of a step response which describes the reaction of the energy system to a step in energy price. This can then lead to a frequency response which can be applied to any arbitrary change in price to estimate the system response. This characterisation technique was adapted by Vandermeulen et al. [19] to be used for predictive controllers of district heating systems and was applied to both building thermal inertia and the network thermal capacity.

Still, a model is needed to predict the behaviour of the DH system during a flexibility activation. District heating models are generally numerically complex [20], which limits the applicability of these flexibility characterisation methods. One cause of computational complexity in a district heating system model is the substation model given the non-linear behaviour of the heat exchanger(s), control system, space heating system, etc. [21]. 
Substation behaviour has been modelled often in the literature. The following papers give examples on the different modelling approaches that can be found in the literature. Giraud et al. [22] modelled the substation as a heat exchanger. On the secondary side of the substation (i.e. the building heating system), they imposed a heating curve to calculate the radiator supply temperature and an ideal controller, always capable of reaching the prescribed temperature. Schweiger et al. [20] developed two different substation models, both consisting of a valve, a heat exchanger and a controller. The first model contains an actual heat exchanger model, while the second imposes a constant primary return temperature as determined by the modeller. Lesko et al. [9] assumed the primary return temperature (i.e. on the network side) to be a linear function of the heat demand and primary supply temperature and did not model a heat exchanger in the substation. Laakkonen et al. 23] estimated the primary return temperature of the substation through a neural network model based on measurements of the heat load in the substation and water temperatures and mass flow rates at the heat production plant. Ikonen et al. 24] assumed a constant temperature drop across the substation. These models range in complexity and detail, with the simpler ones being more attractive from a computational point of view to apply for flexibility characterisation. Yet, it is not known which assumptions can be made to simplify the model without losing valuable information regarding the substation behaviour when activating network flexibility.

\subsection{Research goal and novelties}

The aim of this paper is to evaluate substation models regarding their suitability for network flexibility characterisation by applying the method 


\section{Nomenclature}

BP Bypass

CHP Combined Heat and Power

$\mathrm{DH} \quad$ Distric tHeating

DHC District Heating and Cooling

DHW Domestic Hot Water

EB Energy Balance

HEx Heat Exchanger

LMTD Logarithmic Mean Temperature
Difference

Nom Nominal value

$\mathrm{R}^{2} \mathrm{ES}$ Renewable and Residual Energy Sources

Rad Radiator

SH Space Heating

TES Thermal Energy Storage

from Vandermeulen et al. [19]. The suitability of a model depends on a trade-off between accuracy and complexity. A good model should provide a good estimate of the available energy flexibility, but also be simple enough so that it can be implemented in operational district heating controllers.

To this end, several substation models are evaluated, differing in physical detail and numerical complexity. These models are applied for simulations of a district heating system. The resulting network flexibility activation obtained with each substation model formulation is then evaluated in terms of accuracy and simplicity.

\subsection{Paper outline}

This paper first introduces the concept of network flexibility and introduces the different phases that make up a network flexibility activation in Section 2. These phases will facilitate the analysis of the simulation results. Next, the methodology of the simulation study is presented in Section 3, with 
a description of the different substation models and the simulation case. This discussion is followed by Section 4 , in which the simulations of the different substation models are compared. Finally these results are discussed in Section 5 .

\section{Network flexibility}

In this paper, network flexibility refers to the flexibility that originates from using the thermal capacity of the water that flows in the district heating pipes. The following explanation shows how this flexibility can be activated and is based on the simple district heating system shown in Figure 1 with only one plant, two pipes and one substation with a constant heat demand. Heat losses and diffusion in the network pipes are neglected in this section to simplify the illustration. These effects have a limited influence on the network flexibility activation, as heat losses and heat diffusion effects are small compared to the energy transport in the network.

To activate the network flexibility, the network is charged with a warmer supply temperature for a certain amount of time. Depending on how long this charge takes, different effects will take place. Hence, this section is split up in three sections that discuss a short, long and very long charge, respectively. It is also possible to create network flexibility by first discharging the network, i.e. temporarily inject a colder supply temperature in the network. However, in this paper this variation is not analysed, though it could be the topic of future research. Only a higher supply temperature is applied to the network, as it is more frequently used to prevent morning peaks [25] and there is a guarantee that the required energy can at all times be delivered to the 
customers. From now on, the Reference case refers to the case in which there is no flexibility activation, whereas in the Flexibility case, there is a flexibility activation.

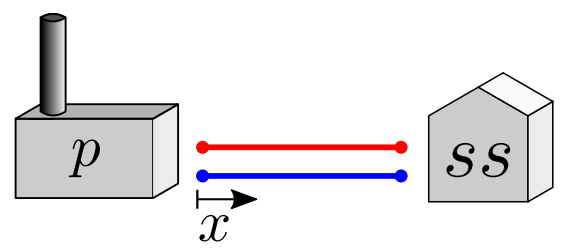

Figure 1: The simple network used to explain the principle of network flexibility. On the left is the heat production plant (p), connected by the supply pipe (in red) and the return pipe (in blue) to the building with substation (ss) on the right.

\subsection{Short charge}

When it is interesting to store energy, e.g. the energy price is low at the moment, but will increase soon, the temperature of the water passing through the plant can be raised above its normal level, as is done in the charge phase (phase 1 in Figure 2). This rise in temperature increases the thermal energy content of the supply side of the network, as is shown in Equation 1. This equation calculates the enthalpy of the entire network at a certain point in time by integrating the energy content of the water along the length of all network pipes.

$$
\left.E_{\text {net }}(t)=\int_{\text {net }} c_{p}\left(\left(T_{\text {sup }}(x, t)\right)-T_{\text {sup }, \text { ref }}\right)+\left(T_{\text {ret }}(x, t)-T_{\text {ret }, \text { ref }}\right)\right) \rho A(x) d x
$$

Hence, by increasing the supply temperature, the network is charged. At a later instance, the higher supply temperature arrives at the substation (phase 2 in Figure 2). What happens in the substation can explained as 

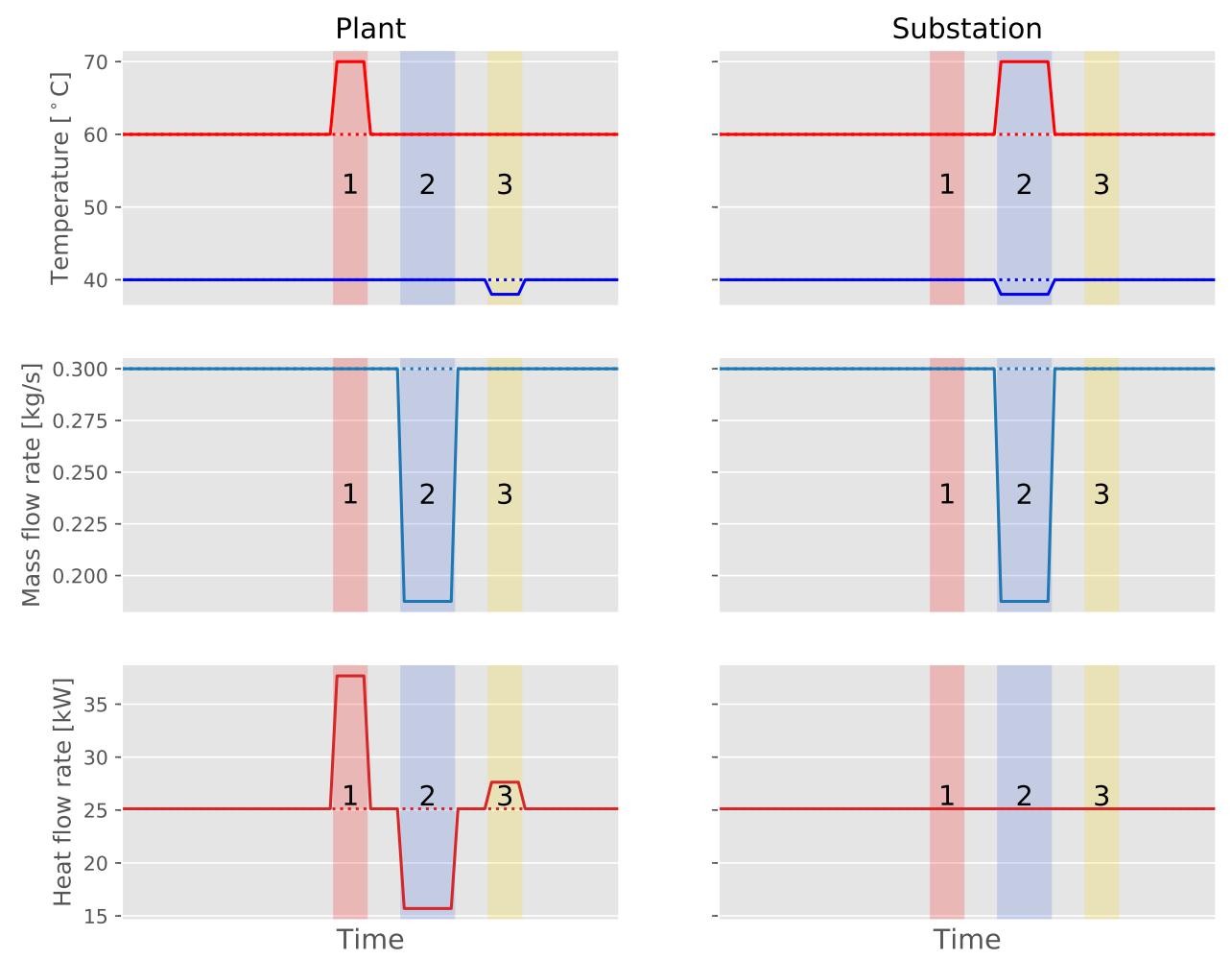

Figure 2: An illustration of the principle of network flexibility, in case there are no heat losses nor heat diffusion, a single substation with a constant heat demand and a short charge. The numbers indicate the three different s: 1) the charge phase, 2) the main discharge phase and 3) the rebound phase. The supply and return temperatures, the mass flow rates and the heat flow rates are shown in the top, middle and bottom row, respectively. The left and right column show the situation at the plant and at the substation, respectively. The dotted lines indicate the reference situation when there would be no activation of network flexibility. This figure is only an illustration and not based on simulation.

follows. The LMTD-model for a counter-flow heat exchanger states that the average temperature difference between the primary and secondary side and the heat transfer are calculated in Equations 2 and 3 , respectively. $\Delta T_{a}$ and 
$\Delta T_{b}$ are the differences between the incoming and outgoing temperatures on each side of the heat exchanger, as indicated in Figure 3.

$$
\begin{gathered}
\Delta T_{l m}=\frac{\Delta T_{a}-\Delta T_{b}}{\log \frac{\Delta T_{a}}{\Delta T_{b}}} \\
\Delta \dot{Q}=\Delta T_{l m} U A
\end{gathered}
$$

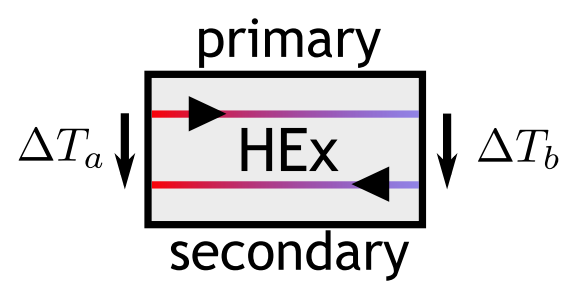

Figure 3: A counter-flow heat exchanger.

As the heat demand remains the same, Equation 3 shows that $\Delta T_{l m}$ should remain the same as well (assuming $U A$ remains the same as well). If the temperatures at the secondary side do not change, a higher primary supply temperature causes $\Delta T_{a}$ to increase. To keep $\Delta T_{l m}$ constant, $\Delta T_{b}$ should decrease. This leads to a lower primary return temperature leaving the heat exchanger.

Hence, the return temperature exiting the substation heat exchanger is now lower than before. To maintain the correct delivery of heat to the building, the mass flow rate through the substation is lowered, as is shown in Equation 4 and in phase 2 of Figure 2. 


$$
\begin{gathered}
\dot{Q}_{\text {dem }}(t)=\dot{m}_{\text {prim }}(t) c_{p}\left(T_{\text {sup }, \text { prim }}(t)-T_{\text {ret }, \text { prim }}(t)\right) \\
=\quad \searrow \quad \searrow
\end{gathered}
$$

The plant sees this lowering of the mass flow rate almost immediately. As the charging is short in this case, the supply temperature at the plant has fallen back to its normal level at that time. Equation 5 shows that a lower plant heating power compared to the reference case is reached. Hence, energy flexibility was created as the network was first charged (phase 1) to then be discharged at a later time (phase 2), which is referred to as the main discharge phase.

$$
\begin{aligned}
& \dot{Q}_{\text {plant }}(t)=\dot{m}_{\text {plant }}(t) c_{p}\left(T_{\text {plant }, \text { sup }}(t)-T_{\text {plant }, \text { ret }}(t)\right) \\
& \searrow \quad \searrow \quad=
\end{aligned}
$$

Lastly, a third stage comprises the arrival of the lower return temperature at the plant (phase 3 in Figure 2). Due to the short duration of the charge, the mass flow rate has gone back to its normal level at this time. The plant heat output will have to increase the heat injection to compensate for the lower return temperature, as is shown by Equation 6. This results in a rebound effect and hence this phase is referred to as the rebound phase.

$$
\begin{gathered}
\dot{Q}_{\text {plant }}(t)=\dot{m}_{\text {plant }}(t) c_{p}\left(T_{\text {sup }, \text { plant }}(t)-T_{\text {ret,plant }}(t)\right) \\
\nearrow= \\
=\quad=\quad \nearrow
\end{gathered}
$$


A possible application of the supply temperature pulse can be to charge the network before the morning peak in heat demand, thereby avoiding the activation of expensive and/or polluting peak plants during the morning peak, as the required heat injection is reduced during the discharge phase, coinciding with the morning peak period.

Note that the flexibility does not only appear in the form of thermal energy. It also appears in the form of reduced pumping power, as the mass flow rate and pressure drop over the network is decreased during the discharge phase. Additionally, network flexibility can be used to bypass mass flow rate constraints in the system during peak periods. However, these aspects of flexibility are not treated any further in this paper.

\subsection{Long charge}

In case the supply temperature pulse is longer, the three phases (the charge, discharge and rebound phase) start to overlap, creating new phases. This case is shown in Figure 4

The higher supply temperature is now injected for a longer time into the network. As a result, the higher supply temperature has already reached the substation before the plant stops charging the network. This causes the discharge phase to begin, i.e. the substation starts reducing the mass flow rate, while the supply temperature pulse still continues (indicated by phase 4 in Figure (4). The plant heat injection is now given by Equation 7. As a result, the supply temperature is still higher than its normal level, while the mass flow rate is lower. These two effects change the plant heat injection in opposite directions. As is derived in Equation 7, the plant heat output depends on the temperature difference at the plant and at the substation. 

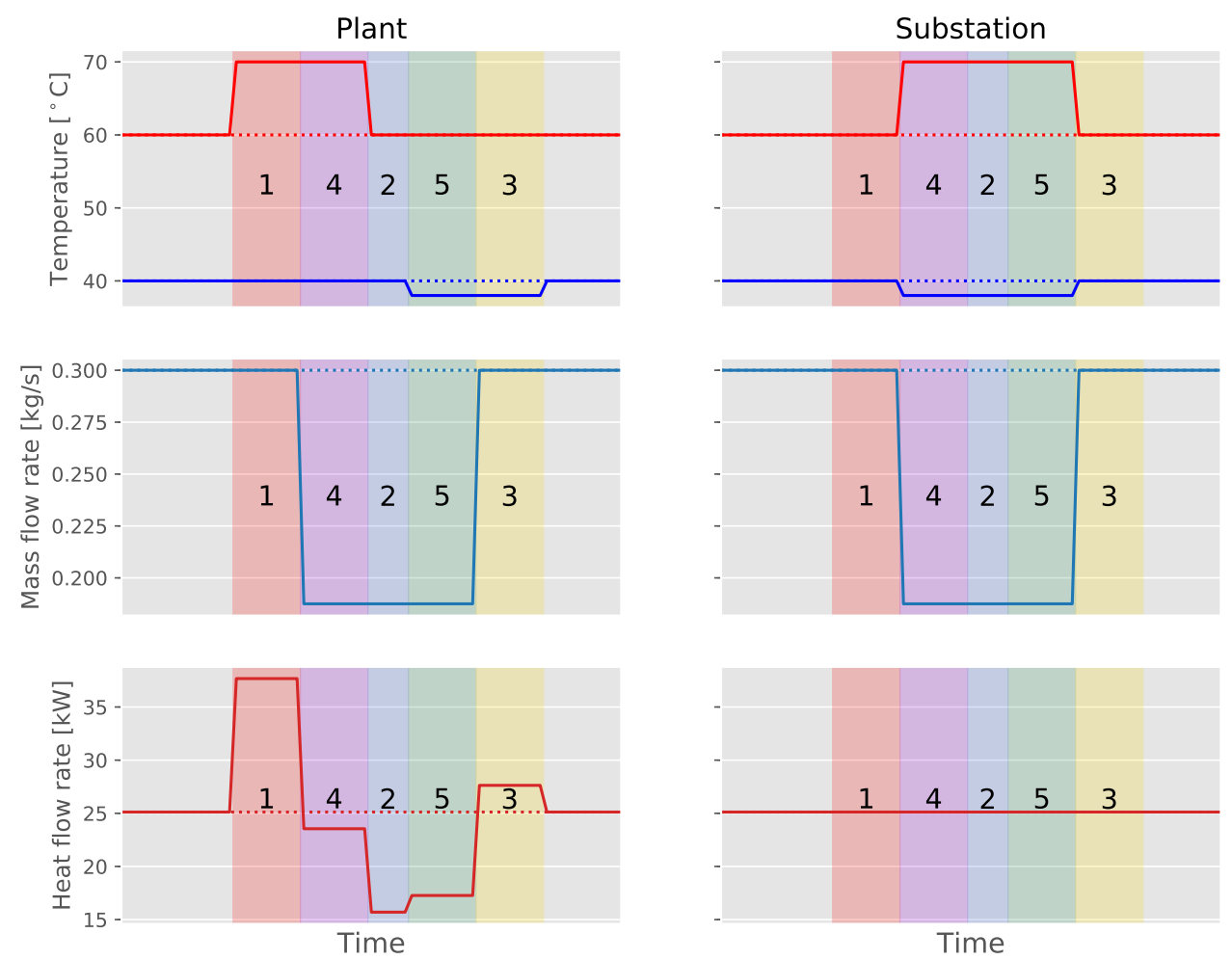

Figure 4: An illustration of the principle of network flexibility, in case there are no heat losses nor heat diffusion, a single substation with a constant heat demand and a long charge. The numbers indicate the five different phases: 1) the charge phase, 2) the main discharge phase, 3 ) the rebound phase, 4) the early discharge phase and 5) the late discharge phase. The supply and return temperatures, the mass flow rates and the heat flow rates are shown in the top, middle and bottom row, respectively. The left and right column show the situation at the plant and at the substation, respectively. The dotted lines indicate the reference situation when there would be no activation of network flexibility. This figure is only an illustration and not based on simulation.

At this moment in time, the temperature difference at the plant is smaller than at the substation and hence the plant heat output is lower than the heat demand. This leads to a a small discharge of the network and hence 
this phase is referred to as the early discharge phase.

$$
\begin{aligned}
\dot{Q}_{\text {plant }}(t) & =\dot{m}_{\text {plant }}(t) c_{p}\left(T_{\text {plant }, \text { sup }}(t)-T_{\text {plant }, \text { ret }}(t)\right) \\
& =\frac{\dot{Q}_{\text {dem }}}{T_{\text {prim,sup }}-T_{\text {prim }, \text { ret }}}\left(T_{\text {plant }, \text { sup }}(t)-T_{\text {plant }, \text { ret }}(t)\right)
\end{aligned}
$$

Another way to interpret the early discharge phase is by examining the energy content of the network. The supply pipe is charged during the charge phase (phase 1). But as soon as the higher supply temperature has reached the substation (phase 4), all of the water in the supply pipe is at the higher temperature and the supply pipe is fully charged. The substation now injects

colder water into the return pipe, discharging the pipe (see Equation 1). The energy content of the supply pipe no longer changes, but the energy content of the return pipe starts decreasing. Hence, during the overlap of the two phases, the total energy content of the network also decreases.

Just like the charge and discharge phase, the discharge and rebound phase also start to overlap (phase 5). While the substation is still causing a reduced mass flow rate, the lower return temperature has already arrived at the plant. Again these two effects are combined, leading to a reduced discharge. This phase is called the late discharge phase.

\subsection{Very long charge}

In case the charging lasts even longer, the overlap between the phases becomes even larger. Figure 5 illustrates how the discharge phase is always overlapping, either with the charge phase, the rebound phase or both at the same time. In case all three phases overlap, there is no difference in plant heat injection compared to the reference case. The reduction in mass flow rate is 
compensated completely by the increased temperature difference across the plant. Hence, this phase is referred to as the neutral phase.

With respect to the energy content of the network, the following interpretation holds; the supply pipe has been completely charged by the end of phase 1 , while the return pipe has been completely discharged by the end of phase 4. Hence, as long as the plant supply temperature does not change, the energy content of the network remains constant (phase 6).

\section{Methodology}

The aim of this paper is to find a trade-off between substation model complexity and accuracy regarding network flexibility characterisation. Hence,

four different residential building substation models are analysed in this study and are described in Section 3.1. In Section 3.2 the energy flexibility characterisation technique that is applied in this research is described. The simulation case study to test the different substation models and the sizing of the different components in that case study is presented in Section 3.3. An overview of all settings relevant to the simulations is given in Section 3.4 .

\subsection{Substation models}

In this study, a substation is defined as the interface between the building heating system and the district heating network. However, in the substation models that are presented, a part of the building heating system is modelled as well, as it influences the substation behaviour and, as a consequence, the entire district heating system. Conversely, the behaviour of the building structure is neglected in this paper for simplicity. The heat demand (both SH 

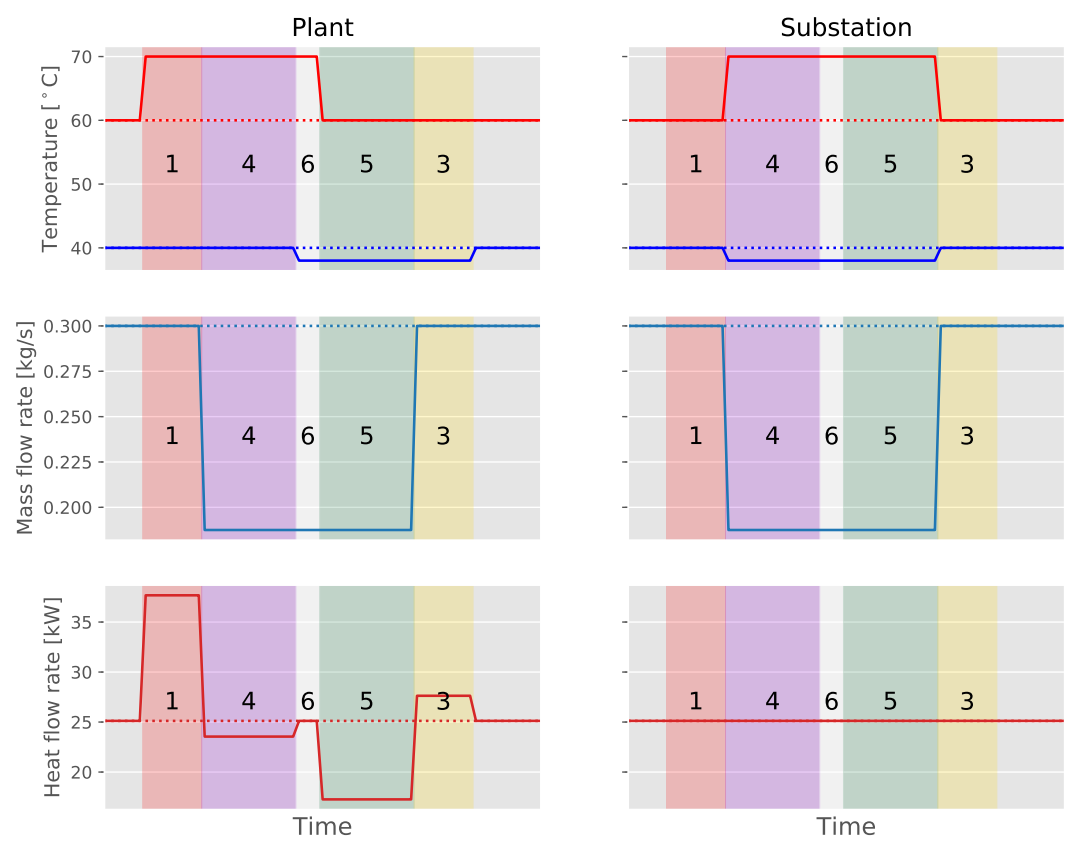

Figure 5: An illustration of the principle of network flexibility, in case there are no heat losses nor heat diffusion and a single substation with a constant heat demand and a very long charge phase. The numbers indicate the five different phases: 1) the charge phase, 3) the rebound phase, 4) the early discharge phase, 5) the late discharge phase, 6) the neutral phase . The supply and return temperatures, the mass flow rates and the heat flow rates are shown in the top, middle and bottom row, respectively. The left and right column show the situation at the plant and at the substation, respectively. The dotted lines indicate the reference situation when there would be no activation of network flexibility. This figure is only an illustration and not based on simulation.

and DHW) are assumed to be known in advance. A more detailed description of the SH and DHW heat demand profiles is given in Section 3.3 .

The substation modelling was limited to the thermal behaviour, i.e. no momentum balance equations are included in the model. By leaving out these equations, the valves in the substation can be modelled as ideal mass 
flow sources. These sources simply prescribe the mass flow rate that should be flowing through, hence making momentum balances unnecessary.

\subsubsection{The Full substation model}

This substation, shortly referred to as the Full model in the remainder of the paper, is the most detailed of the models. The hydraulic scheme of this model can be found in Figure 6. The substation consists of two heat exchangers (HEx), one for SH and one for DHW. In this paper, these two heat exchangers are put in parallel, corresponding to typical configurations [26, 27, 28], but other substation layouts are possible as well [6]. The SH and DHW heat exchangers are both counter-flow and modelled with an $\epsilon-N T U$ model, the equations of which are shown by Equations $8+15$.

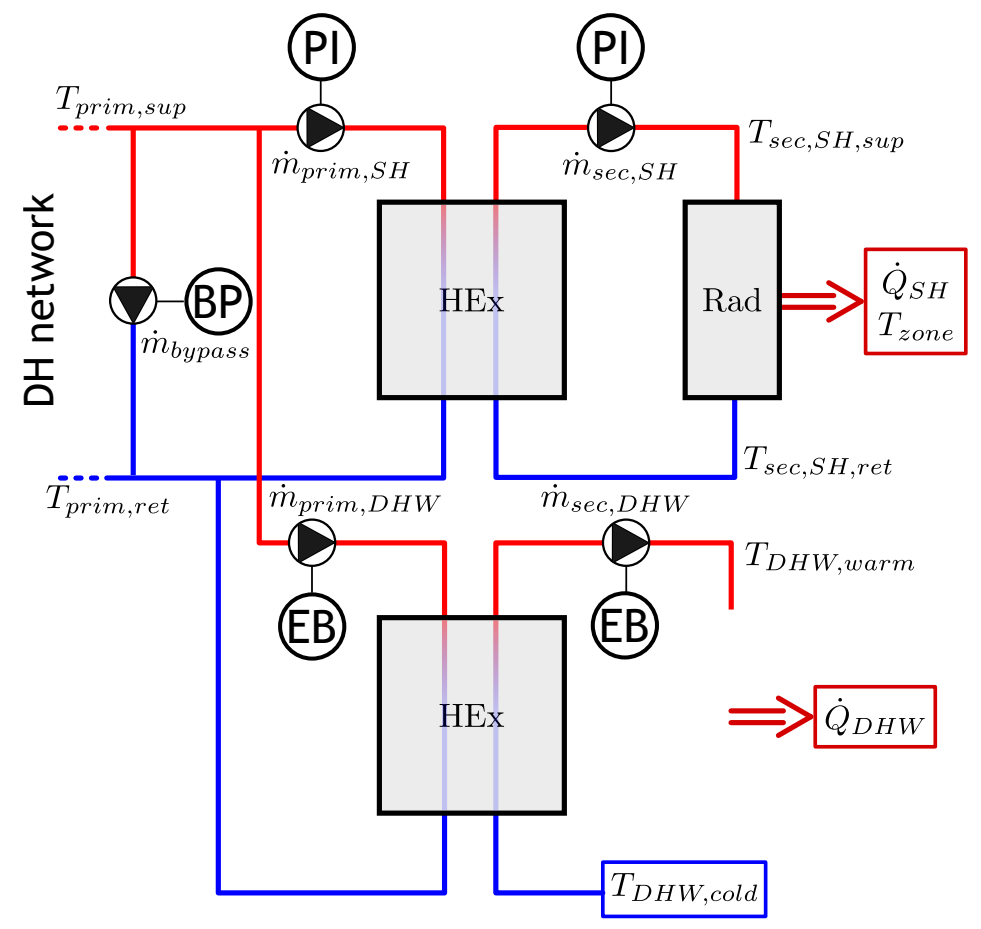

Figure 6: The Full substation model 


$$
\begin{gathered}
C_{\text {min }}=\min \left(\dot{m}_{\text {prim }} c_{p}, \dot{m}_{\text {sec }} c_{p}\right) \\
C_{\text {max }}=\max \left(\dot{m}_{\text {prim }} c_{p}, \dot{m}_{\text {sec }} c_{p}\right) \\
C^{*}=\frac{C_{\text {min }}}{C_{\text {max }}} \\
U A=\frac{K_{H E x}}{\dot{m}_{\text {prim }}^{-0.7}+\dot{m}_{\text {sec }}^{-0.7}} \\
N T U=\frac{U A}{C_{\min }} \\
\epsilon=\frac{1-e^{-N T U\left(1-C^{*}\right)}}{1-C^{*} e^{-N T U *\left(1-C^{*}\right)}} \\
\dot{Q}_{\text {max }}=C_{\text {min }}\left(T_{\text {max }}-T_{\text {min }}\right) \\
\dot{Q}_{H E x}=\epsilon \dot{Q}_{H E x, \max }
\end{gathered}
$$

The SH system is modelled as one lumped radiator that provides heat to the entire building. The water flowing through this radiator is heated by the district heating network through the $\mathrm{SH}$ heat exchanger. The radiator model is described by Equations 16,18, As is explained in Section 3.3, the building zone temperature profile $T_{z o n e}$, corresponding to the heat demand $\dot{Q}_{S H}$ is known, but not constant in time.

$$
\begin{gathered}
\dot{Q}_{S H}=U A_{\text {rad }}\left(T_{\text {rad }}-T_{\text {zone }}\right)^{1.3} \\
T_{\text {rad }}=\frac{T_{\text {sec }, \text { SH,ret }}+T_{\text {sec }, S H, \text { sup }}}{2} \\
\dot{Q}_{S H}=\dot{m}_{s e c, S H} c_{p}\left(T_{\text {sec }, S H, \text { sup }}-T_{\text {sec }, S H, r e t}\right)
\end{gathered}
$$

The mass flow rate on the primary side of the $\mathrm{SH}$ system $\dot{m}_{\text {prim,SH }}$ is controlled by a PI-controller. The controller aims at keeping the temperature 
supplied to the radiator $T_{\text {sec,SH,sup }}$ as close as possible to the value prescribed by a heating curve. On the secondary side, a second PI-controller mimics the behaviour of a thermostatic valve. The controller regulates $\dot{m}_{\text {sec }, D H W}$ such that the known heat demand $\dot{Q}_{S H}$ is delivered by the radiator to the building. This is slightly different from reality, where a thermostatic valve aims at keeping the zone temperature within comfort limits. This change was made due to the absence of a building structure model.

The DHW system is a direct system which means that there is no water tank, and all heat demand should be delivered instantaneously. The temperatures at the DHW side, indicated by $T_{\text {sec,DHW,ret }}$ and $T_{\text {sec,DHW,sup }}$, are the temperatures of cold and warm tap water and are taken to be known and constant in time. The DHW heat demand is known, but not constant in time.

The control of this DHW system is as follows. As already mentioned, there are no valves in the substation model. Instead, they are replaced by ideal mass flow sources. The mass flow rate on the secondary side of the heat exchanger is determined by the energy balance (EB) in Equation 19. This equation leads to the required mass flow rate as the heat demand $\dot{Q}_{D H W}$ and the temperatures $T_{\text {sec,DHW,ret }}$ and warm tap water setpoint $T_{\text {sec,DHW,sup }}$ are known in advance.

$$
\dot{m}_{s e c, D H W}=\frac{\dot{Q}_{D H W}}{\left(T_{\text {sec }, D H W, \text { sup }}-T_{\text {sec }, D H W, r e t}\right) c_{p}}
$$

At the primary side, a similar control takes place. The heat demand that should be delivered is still $\dot{Q}_{D H W}$. Yet, the temperatures are not known in advance, the primary supply temperature $T_{\text {prim,DHW,sup }}$ is determined by 
the district heating network (i.e. the temperature of the water that arrives at the substation), while $T_{\text {prim, } D H W, r e t}$ is the temperature leaving the DHW heat exchanger. Still, a very similar control was implemented here, based on the energy balance in Equation 20. The temperatures $T_{\text {prim,DHW,sup }}$ and $T_{\text {prim,DHW,ret }}$ are measured by temperature sensors. Hence, this energy balance will be a kind of feedback control, changing $\dot{m}_{\text {prim, } D H W}$ until $\dot{Q}_{D H W}$ is reached.

$$
\dot{m}_{\text {prim }, D H W}=\frac{\dot{Q}_{D H W}}{\left(T_{\text {prim }, D H W, \text { sup }}-T_{\text {prim }, D H W, r e t}\right) c_{p}}
$$

Finally, the bypass ensures that at all times sufficiently warm water is available at the substation. In the model, the bypass mass flow rate is set to $1 \%$ of the nominal value of $\dot{m}_{\text {prim,SH }}$. The bypass is activated as soon as $T_{\text {sup,prim }}$ falls $10^{\circ} \mathrm{C}$ below the nominal district heating supply temperature.

\subsubsection{The No Rad substation model}

The No Rad substation model still has the same DHW system, bypass system and heat exchanger model (Equations 8,15), but no longer includes a radiator model. The structure of the model is presented in Figure 7. The radiator is replaced by a look-up table, which is based on the function shown in Equation 21. This function is described in detail in Section 3.1.5. The secondary mass flow rate $\dot{m}_{s e c, S H}$ is kept constant and equal to its nominal

value $\dot{m}_{\text {sec,SH,nom. }}$. On the primary side, the $\mathrm{SH}$ control system is replaced by the energy balance shown in Equation 22, This energy balance prescribes the primary mass flow rate needed to deliver the requested heat.

$$
T_{s e c, S H, r e t}=f_{1}\left(\dot{Q}_{S H}\right)
$$




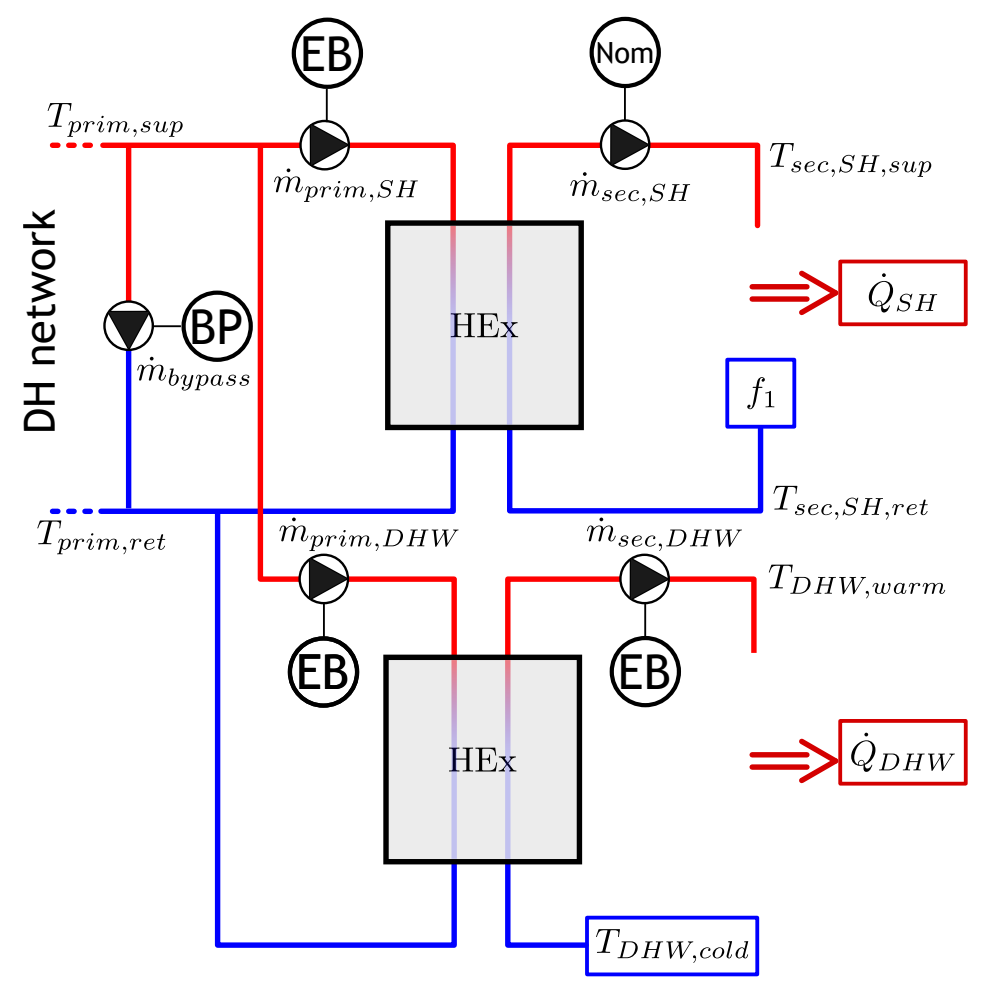

Figure 7: The No Rad substation model

$$
\dot{m}_{\text {prim }, S H}=\frac{\dot{Q}_{S H}}{\left(T_{\text {prim }, \text { SH,sup }}-T_{\text {prim }, S H, \text { ret }}\right) c_{p}}
$$

\subsubsection{The No HEx substation model}

In the No HEx substation model, the heat exchangers have been removed and the two systems, SH and DHW have been taken together, as shown in Figure 8 . The heat exchangers are replaced by a look-up table that contains the primary return temperature based on the function shown in Equation 23. This function is described in more detail in Section 3.1.5. The control of the primary mass flow rate is based on the energy balance in Equation 24. Note that $f_{2}$ in Equation 23 only depends on the $\mathrm{SH}$ heat demand, 
and not on the DHW demand. This choice was made as this simplifies the calculation of $f_{2}$ significantly, while having very limited consequences regarding the performance of this substation model, as will be seen in the results. The bypass system has not changed.

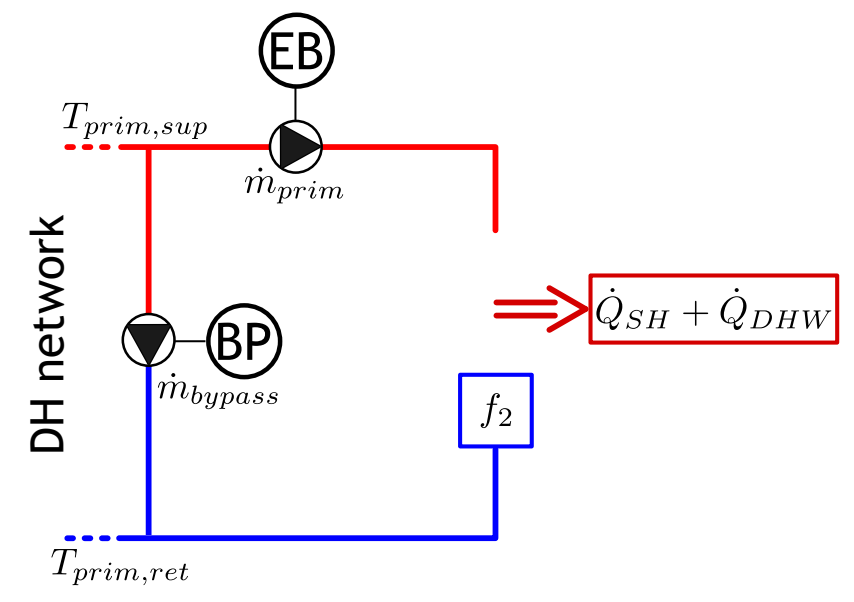

Figure 8: The No HEx substation model

$$
\begin{gathered}
T_{\text {prim }, \text { ret }}=f_{2}\left(\dot{Q}_{S H}, T_{\text {prim }, \text { sup }}\right) \\
\dot{m}_{\text {prim }, \text { sup }}=\frac{\dot{Q}_{S H}+\dot{Q}_{D H W}}{\left(T_{\text {prim }, S H, \text { sup }}-T_{\text {prim }, S H, r e t}\right) c_{p}}
\end{gathered}
$$

\subsubsection{The Cst $\Delta T$ substation model}

In the Cst $\Delta T$ substation model, both heat exchangers have been removed, similar to the No HEx model. However, a different assumption to replace the heat exchangers is made instead. Now, a constant temperature difference $\Delta T$ across the substation is taken, regardless of the heat demand or the incoming supply temperature. This assumption has been made before 
in the literature [19, 24]. Again, the SH and DHW systems have been taken together.

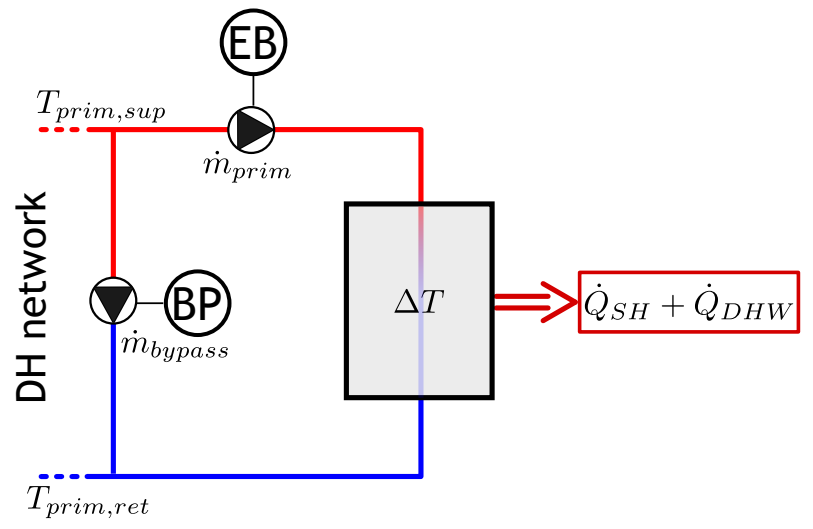

Figure 9: The Cst $\Delta T$ substation model

The primary mass flow rate is then determined as follows:

$$
\dot{m}_{\text {prim }}=\frac{\dot{Q}_{S H}+\dot{Q}_{D H W}}{\Delta T c_{p}}
$$

\subsubsection{Mapping techniques}

The substation models $N o$ Rad and No HEx require functions that map 1) $\dot{Q}_{S H}$ to $T_{s e c, S H, r e t}$, and 2) $\dot{Q}_{S H}$ and $T_{\text {prim,sup }}$ to $T_{\text {prim,ret }}$, respectively. These functions are based on the steady-state heat exchanger and radiator models presented by Equations 8, 15 and 16 18. By setting up the model of the relevant system, and, subsequently, removing all variables other than $\dot{Q}_{S H}$ and $T_{\text {prim,sup }}$ by making appropriate assumptions, the two functions $f_{1}$ and $f_{2}$ can be derived.

For No Rad, only the radiator model is required, as this is sufficient to link $\dot{Q}_{S H}$ to $T_{s e c, S H, r e t}$. Rewriting Equations 16, 18, leads to the following 
expression:

$$
T_{\text {sec }, S H, r e t}=f_{1}\left(\dot{Q}_{S H}\right)=\left[\left(\frac{\dot{Q}_{S H}}{U A_{\text {rad }}}\right)^{\frac{1}{1.3}}+T_{z o n e, n o m}\right]-\left(\frac{\dot{Q}_{S H}}{2 \dot{m}_{s e c, S H, n o m} c_{p}}\right)
$$

To ensure the only variable in this function is $\dot{Q}_{S H}$, it is assumed that $T_{z o n e}$ is always equal to its nominal value, while $\dot{m}_{s e c, S H}$ is the nominal mass flow rate. In the simulation, this function is implemented as a look-up table, with the SH heat demand as input and the corresponding secondary return temperature as output.

For No HEx, both the radiator and heat exchanger model are needed to $\operatorname{link} \dot{Q}_{S H}$ and $T_{\text {prim,sup }}$ to $T_{\text {prim,ret }}$. The radiator model (Equations 16 . 18) and the LMTD model for heat exchangers (Equations 27 and 28), are combined to form the system of equations 29.31 . To ensure the only variables in this system of equations are $\dot{Q}_{S H}$ and $T_{\text {prim,sup }}$, additional assumptions are necessary. It is assumed that $T_{z o n e}$ is equal to its nominal value. $U A_{H E x}$ is also fixed and set to its nominal value, calculated by using the nominal mass flow rates in Equation 11 .

$$
\begin{gathered}
\Delta T_{l m}=\frac{\left(T_{\text {prim }, \text { sup }, \text { nom }}-T_{\text {sec }, \text { SH,sup }}\right)-\left(T_{\text {prim }, \text { ret }}-T_{\text {sec }, \text { SH,ret }}\right)}{\ln \frac{T_{\text {prim }, \text { sup }, \text { nom }}-T_{\text {sec }, \text { SH }, \text { sup }}}{T_{\text {prim }, \text { ret }}-T_{\text {sec }, \text { SH }, \text { ret }}}} \\
\dot{Q}_{S H}=U A_{H E x} \Delta T_{l m} \\
T_{\text {sec }, \text { sup }}=\frac{\dot{Q}_{S H}}{\dot{m}_{\text {sec }, \text { SH,nom }} c_{p}}+T_{\text {sec }, \text { ret }} \\
\xi=\frac{\dot{Q}_{S H}}{\left(\left(T_{\text {prim }, \text { sup }, \text { nom }}-T_{\text {sec }, \text { sup }, S H}\right)-\left(T_{\text {prim }, \text { ret }}-T_{\text {sec }, S H, r e t}\right)\right) U A_{H E x, \text { nom }}} \\
T_{\text {prim,ret }}=f_{2}\left(\dot{Q}_{S H}, T_{\text {prim }, \text { sup }}\right)=\left(T_{\text {prim }, \text { sup }}-T_{\text {sec }, S H, \text { sup }}\right) e^{-\xi}+T_{\text {sec }, S H, \text { ret }}
\end{gathered}
$$


It is important to note that this equation neglects the influence of the DHW system on the primary return temperature of the substation. However, the results will show that this does not severely affect the performance of this function. In the simulation, this function is implemented as a $2 \mathrm{D}$ look-up table, with the SH heat demand and primary supply temperature as inputs and the corresponding primary return temperature as output.

\subsubsection{Summary}

A short summary of the models can be found in Table 3. The left side of this table indicates for each of the the four substation models the presence of heat exchangers and/or a radiator within the model. Where applicable, the function or value replacing that component is written between brackets. The right side of the table indicates the kind of control that is applied, that can either be based on an energy balance equation (EB), a PI-controller (PI) or a constant nominal value (Nom).

Table 3: An overview of the four substation models. In the left part of the table the presence of component models is indicated. On the right side, the type of control for the two sides of the space heating system is indicated.

\begin{tabular}{|c||c|c||c|c|}
\hline Name & HEx & Rad & Primary & Secondary \\
\hline \hline Full & $\mathrm{X}$ & $\mathrm{X}$ & PI & PI \\
\hline No Rad & $\mathrm{X}$ & $\backslash\left(f_{1}\right)$ & $\mathrm{EB}$ & Nom \\
\hline No HEx & $\backslash\left(f_{2}\right)$ & $\backslash$ & $\mathrm{EB}$ & $\backslash$ \\
\hline Cst $\Delta T$ & $\backslash(\Delta T)$ & $\backslash$ & $\mathrm{EB}$ & $\backslash$ \\
\hline
\end{tabular}




\subsection{Flexibility characterisation}

In order to analyse energy flexibility, a means to characterise the available flexibility is required. Several approaches have already been developed, as was discussed in Section 1.1. In this paper, a approach suited for thermal network flexibility in particular [19], is applied. In this approach a supply temperature pulse response is generated, which is defined as the difference between the scenario's with (Flexibility) and without (Reference) supply temperature pulse. An example of the Reference (dotted lines) and Flexibility (full lines) cases is shown in Figure 2.

\subsection{Case description}

This section provides information on the simulations done to evaluate the substation models. In Section 3.3.1, the case study is presented. This case is simulated multiple times with different supply temperature pulses to make sure all effects relevant to network flexibility can be analysed. These different cases are presented in Section 3.3.2. Additionally, information on the sizing of components in the different substations is given in Section 3.3.3.

\subsubsection{The Waterschei district}

The investigated district heating system is based on a fictive district heating network of the Waterschei district in the city of Genk (Belgium), consisting of 1491 buildings. This district is connected to a heat production plant by a transmission pipe of $2806 \mathrm{~m}$ long. Previous work generated realistic occupancy behaviour [29] and heat demand and zone temperature profiles [30] specifically for this district. Hence, the case study presents fictive, yet realistic behaviour. 
To speed up the simulations, all buildings within the district are aggregated into a single building, representing the average building of that district. The aggregation is done as follows; as the heat demand profiles of each building are already known (both SH and DHW) [30, the average heat demand at each point in time is calculated. This average heat demand is then applied to the substation model representing a single building substation. To let this average substation represent the entire district (consisting of $n$ buildings), the requested mass flow rate of the aggregated substation is multiplied by $n$, while the incoming and outgoing temperatures are kept the same. In the end, the DH system model consists only of a heat production plant, one aggregated building (its primary mass flow rate multiplied by the number of buildings in the district) and a supply and return pipe.

The aggregation causes the heat demand profiles to be flattened out in time. Hence, there will be less high peaks in heat demand and fewer moments with no heat demand at all. This will e.g. influence the behaviour of the bypass valve, which only activates in case of extended periods of low heat demand. However, in light of the research goals of this paper, these assumptions are deemed acceptable.

\subsubsection{Charge cases}

To activate network flexibility, the supply temperature is temporarily increased, as is shown in the top graph of Figure 2. A typical Belgian winter day (the $12^{\text {th }}$ of January of the typical meteorological year in Uccle, Belgium) is simulated with a supply temperature pulse that ends at $14 \mathrm{~h} 00$. There are three different cases, with the pulse starting 15, 45 or 60 min earlier, corresponding to a short, long and very long charge, respectively (see Section 2). 
By simulating these three cases, all possible network flexibility phases can be analysed, enabling a complete analysis of the substation models. More simulations were done in the research leading up to this paper (smaller networks, different days, etc.). However, the conclusions of these other cases were the same as the case study presented in this paper and, therefore, only a single case study is retained for presentation in this paper.

\subsubsection{Component sizing}

The different components in the simulated district heating system are sized based on nominal steady-state calculations. The substation should be able to deliver the nominal heat demand of the average building, while the network should be able to deliver the average nominal heat demand multiplied by the number of buildings in the district. By combining this with the nominal temperatures in the network, all components can be sized.

The nominal temperatures are shown in Table 4. These temperatures were based on the definition of $4^{\text {th }}$ generation district heating networks [31] and the recommendations made by Yang et al. [27]. The nominal heat demand of the average building in the Waterschei district is $36 \mathrm{~kW}$.

The nominal mass flow rates in the substations can be calculated as follows:

$$
\dot{m}_{\text {nom }}=\frac{\dot{Q}_{\text {nom }}}{T_{\text {sup }, \text { nom }}-T_{\text {ret }, \text { nom }}}
$$

This equation can be applied to calculate all possible nominal mass flow

rates $\left(\dot{m}_{\text {prim,SH,nom }}, \dot{m}_{\text {sec }, S H, \text { nom }}, \dot{m}_{\text {prim }, D H W, n o m}, \dot{m}_{\text {sec }, D H W, n o m}\right)$, by using the corresponding nominal heat demand and temperatures.

The same can be done to determine $K_{H E x, D H W}$ and $K_{H E x, S H}$ which in- 
Table 4: The nominal temperatures in the substations.

\begin{tabular}{|l|l|}
\hline$T_{\text {prim,sup,nom }}$ & $57^{\circ} \mathrm{C}$ \\
\hline$T_{\text {prim,ret }, \text { nom }}$ & $30^{\circ} \mathrm{C}$ \\
\hline$T_{\text {sec }, \text { SH,sup }, \text { nom }}$ & $47^{\circ} \mathrm{C}$ \\
\hline$T_{\text {sec }, \text { SH,ret,nom }}$ & $35^{\circ} \mathrm{C}$ \\
\hline$T_{\text {sec }, \text { DHW,sup }, \text { nom }}$ & $50^{\circ} \mathrm{C}$ \\
\hline$T_{\text {sec }, \text { DHW,ret }, \text { nom }}$ & $10^{\circ} \mathrm{C}$ \\
\hline$T_{\text {zone }, \text { nom }}$ & $18^{\circ} \mathrm{C}$ \\
\hline
\end{tabular}

dicate the size of the counter-flow heat exchangers:

$$
\dot{Q}_{\text {peak }}=\frac{K_{H E x}}{\dot{m}_{\text {prim }}^{-0.7}+\dot{m}_{\text {sec }}^{-0.7}} \frac{\left(T_{\text {prim }, \text { sup }}-T_{\text {sec }, \text { sup }}\right)-\left(T_{\text {prim }, \text { ret }}-T_{\text {sec }, \text { ret }}\right)}{\ln \left(\frac{T_{\text {prim }, \text { sup }}-T_{\text {sec }, \text { sup }}}{T_{\text {prim }, \text { ret }}-T_{\text {sec }, \text { ret }}}\right)}
$$

The PI controllers in the Full substation were tuned according to the good gains method [32]. The pipe sizes were determined based on the nominal heat demand of the district and the nominal temperatures (Table 4). Based on the maximum allowed mass flow rate corresponding to a pipe diameter as prescribed by the IsoPlus catalogue [33], pipe diameters were selected. The parameters describing the pipe wall and insulation properties were also taken from this catalogue.

The $\Delta T$ in the Cst $\Delta T$ substation is taken to be the nominal temperature, $27^{\circ} \mathrm{C}$ in all cases.

\subsection{Simulation set-up}

As mentioned in Section 3.3.1, the simulated district heating system consists of one building, one plant and one supply and return pipe. The entire 
network model is implemented in Modelica and based on component models readily available in the IDEAS [34] and IBPSA [35] libraries. The building is represented by one of the substation models introduced in Section 3.1 . The plant is assumed to be an ideal heat source, capable of delivering the requested supply temperature, no matter the incoming return temperature or mass flow rate. The plant model thus neglects limits on the heat output and the ramping rates that might be imposed on actual district heating plants. The model used for the district heating pipes is the plug-flow model developed by van der Heijde et al. [36].

Although the substation models themselves were not validated, the component models of which they are composed, have been validated. The behaviour of the substation models was verified and compared to the literature and a more thorough validation of these models will follow in future research.

The total simulation period of one case is 4 days, of which the first two days are taken as an initialisation period. This ensures that any effects caused by the initialisation have died out by the time the supply temperature pulse takes place (on the third day at 14h00). The fourth day is simulated as well to make sure all effects of the pulse have disappeared by the end of the simulation. To simulate, the explicit Euler solver was used with a time step of $1 \mathrm{~s}$.

The height of the supply temperature pulse that creates the flexibility (see Figure 2) is always $10^{\circ} \mathrm{C}$. The shape of the pulse is a perfect block, i.e. the supply temperature changes instantly $10^{\circ} \mathrm{C}$ higher/lower. To comply with the standard EN13941, the change in supply temperature should be limited to $10^{\circ} \mathrm{C} / \mathrm{h}$, but this is not included in this paper. 


\section{Results}

To analyse the different substation models, Figures 11- 14 show the different simulation cases. These figures clearly show the three phases (charge, discharge and rebound) and their possible overlap. To help interpret the figures, Figure 10 shows the colouring of the phases in case of the referenceFull model. A visual analysis of these graphs provides a means to compare the different substation models regarding their ability to correctly represent network flexibility behaviour. Besides a visual analysis, the figures are interpreted with the help of simplified model equations. In these equations, heat losses and diffusion in the network pipes are neglected, so that the temperatures at the substation and the plant are the same. This only introduces small errors, but simplifies the equations substantially. Additionally, the hat demand is assumed constant, which is in this case a good assumption (see lower right graph of Figure 11). Furthermore, these equations use the subscripts ref and flex. The former refers to the normal value of a variable. The latter refers to the value influenced by the supply temperature pulse. For example, $T_{\text {sup }, \text { ref }}$ refers to the normal supply temperature in the network, whereas $T_{\text {sup, flex }}$ refers to the value of the network supply temperature during the pulse, i.e. $10^{\circ} \mathrm{C}$ higher. $\dot{m}_{r e f}$ refers to the normal mass flow rate in the network, while $\dot{m}_{f l e x}$ refers to the reduced mass flow rate during the early, main and late discharge phases.

The analysis of the results is split up according to a short, long and very long charge (similar to the structure of Section 2). 


\section{Charge \\ Early discharge \\ Main discharge \\ Neutral \\ Late discharge \\ Rebound}

Figure 10: The colours corresponding to the different network flexibility phases.

\subsection{Short charge}

Considering the short charge in Figure 11, all substations except Cst $\Delta T$ have a response as was described in Section 2. The different behaviour of Cst $\Delta T$ is caused by its main assumption: a constant temperature difference across the substation heat exchanger. Consequently, the mass flow rate in $C s t \Delta T$ does not change when a higher supply temperature arrives, as opposed to the other substation models. Instead, Cst $\Delta T$ passes the pulse on to the return line. The discharge phase only begins when this higher return temperature arrives back at the plant, and the plant can reduce the heat output due to a lower temperature difference between the return temperature and the required supply temperature. As a conclusion, Figure 11 already shows that Cst $\Delta T$ is not sufficient to model network flexibility. This substation model does not follow the principle of network flexibility, i.e. depending on a higher return temperature instead of a lower mass flow rate. As a consequence, the timing of Cst $\Delta T$ is very different from the other substation models.

When comparing the remaining two reduced substation models, No Rad and No HEx, with the reference model, Full, the performance of the two reduced models is very similar. The performance of these models mostly depends on 

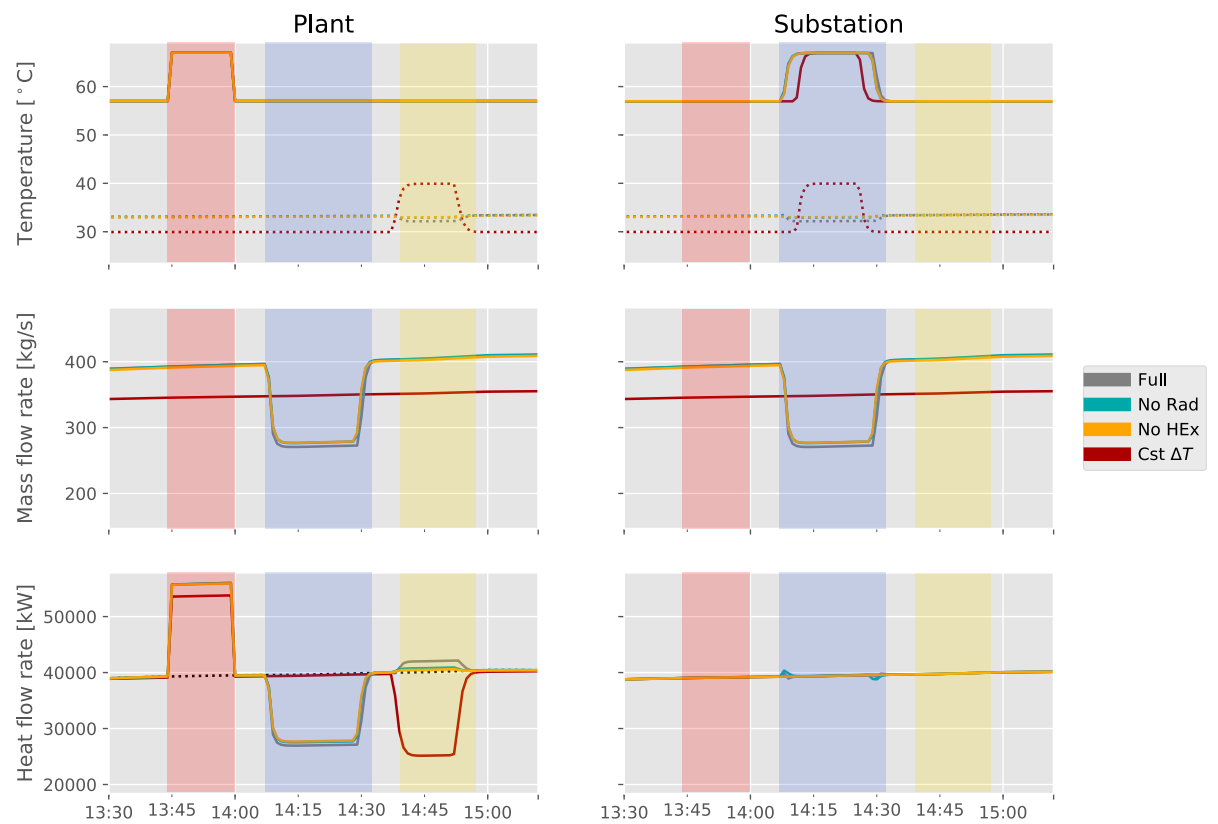

Figure 11: The simulation results of a short charge. From top to bottom, temperatures, mass flow rates and heat flow rates are shown. On the left side, these results are shown for the plant side of the network, on the right for the substation side.

their ability to estimate the return temperature. Figure 11 shows that when the normal supply temperature enters the substation, the predicted return temperature is very good (with an error lower than $0.05{ }^{\circ} \mathrm{C}$ for both reduced models), when the higher supply temperature enters the substation, there is a larger deviation of about $0.5^{\circ} \mathrm{C}$.

However, the consequences of these deviations depend on the network flexibility phase. In the rebound phase, the reduced models show a relatively large error in the increase of the plant heat injection compared to the Full model. It seems that the extra heat injection of the plant during the rebound phase is very sensitive to errors in the return temperature estimation. 
As is shown in Equation $34, \dot{Q}_{\text {rebound }}$ depends on the difference between the return temperature in the Reference and Flexibility case, which is very small to begin with. An error of $0.5^{\circ} \mathrm{C}$ in the estimation of $T_{\text {prim,ret,flex }}$ can thus lead to large relative errors, as is illustrated in Figure 12, To derive Equation 34. note that the heat demand during the rebound phase is delivered with the reference temperatures and reference mass flow rate.

By contrast, there seems to be little or no error at all in the charge phase. Indeed, the extra heat injection during the charge phase does not depend on $T_{\text {ret,flex }}$ at all, as is shown in Equation 35 (derived in the same way as Equation 34. It only depends on $T_{\text {ret,ref }}$ which is estimated well. The reduction in heat injection during the main discharge phase does depend on $T_{\text {ret,flex }}$ (Equation 36), but is not as sensitive as during the rebound phase. Here, the error of $0.5^{\circ} \mathrm{C}$ is small compared to the relevant temperature differences, which are shown in Equation 36. Hence, this error is of little consequence and no large deviations can be seen during the main discharge phase.

$$
\begin{aligned}
\dot{Q}_{\text {rebound }} & =\dot{Q}_{\text {flex }, \text { rebound }}-\dot{Q}_{\text {ref }, \text { rebound }} \\
& =\dot{m}_{\text {ref }} c_{p}\left(T_{\text {sup }, \text { ref }}-T_{\text {ret }, \text { flex }}\right)-\dot{Q}_{\text {dem }} \\
& =\frac{\dot{Q}_{\text {dem }}}{T_{\text {sup }, \text { ref }}-T_{\text {ret }, \text { ref }}}\left(T_{\text {sup }, \text { ref }}-T_{\text {ret }, \text { flex }}\right)-\dot{Q}_{\text {dem }} \\
& =\dot{Q}_{\text {dem }} \frac{T_{\text {ret }, \text { ref }}-T_{\text {ret }, \text { flex }}}{T_{\text {sup }, \text { ref }}-T_{\text {ret }, \text { ref }}} \\
\dot{Q}_{\text {charge }} & =\dot{Q}_{\text {dem }} \frac{T_{\text {sup }, \text { flex }}-T_{\text {sup }, \text { ref }}}{T_{\text {sup }, \text { ref }}-T_{\text {ret }, \text { ref }}} \\
\dot{Q}_{\text {main discharge }} & =\dot{Q}_{\text {dem }} \frac{\left(T_{\text {sup }, \text { ref }}-T_{\text {sup }, \text { flex }}\right)+\left(T_{\text {ret }, \text { flex }}-T_{\text {ret }, r e f}\right)}{T_{\text {sup }, \text { flex }}-T_{\text {ret }, \text { flex }}}
\end{aligned}
$$




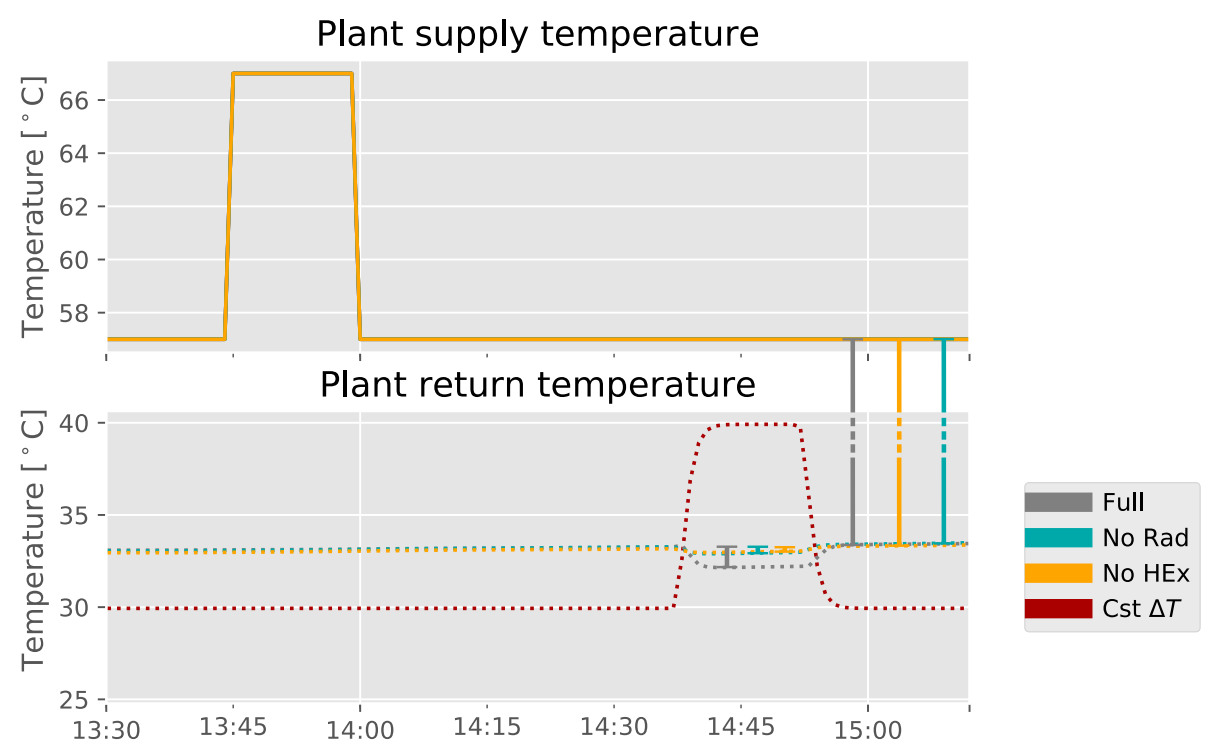

Figure 12: The water temperatures at the plant in case of the short charge. The supply and return temperatures are shown in the top and bottom figure, respectively. The extra vertical lines indicate the temperature differences in Equation 34 for the Full, No Rad and No HEx models. The first three (short) lines indicate the numerator in Equation 34 for each substation model, while the three last (long) lines indicate the denominator. Note that there is barely any difference in length between the long lines, meaning this temperature difference is not sensitive to errors in the return temperature estimation. But the short lines show that an error of about $0.5{ }^{\circ} \mathrm{C}$ leads to a line that is not even half as long as the Full model, leading to a large sensitivity.

\subsection{Long charge}

During a long charge (Figure 13), the three original phases overlap and new phases appear. The discharge phase is now split up into three sub-phases, the early, main and late discharge phases. Considering the Cst $\Delta T$ model, the conclusions remain the same. This model behaves completely different from the Full model and is hence not a good option. The other two reduced 

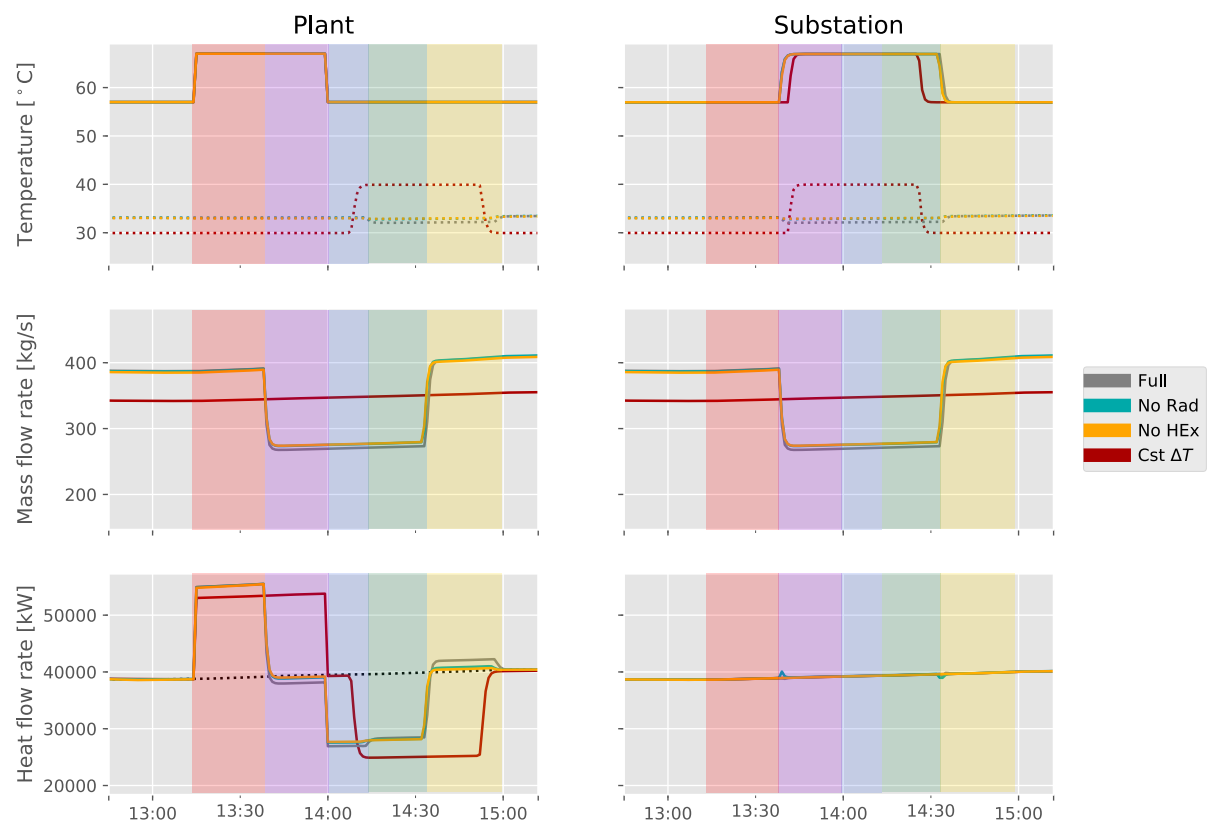

Figure 13: The simulation results of a long charge. From top to bottom, temperatures, mass flow rates and heat flow rates are shown. On the left side, these results are shown for the plant side of the network, on the right for the substation side.

models require a more in-depth analysis. The reduced models still show the same deviations during the charge, main discharge and rebound phases as in the short charge case. During the early discharge phase, it seems that there are relatively large errors which means that the reduction in plant heat injection is very sensitive to small errors in the return temperature estimation of the substation model, similar to the rebound phase. This is also shown in Equation 37. During the late discharge phase, however, there seems to be very little error in the estimation of the extra plant heat injection. Again, this is confirmed by analysing the temperature differences relevant to this 
phase, as is done in Equation 38 .

$$
\begin{gathered}
\dot{Q}_{\text {early discharge }}=\dot{Q}_{\text {dem }} \frac{T_{\text {ret }, \text { flex }}-T_{\text {ret }, \text { ref }}}{T_{\text {sup }, \text { flex }}-T_{\text {ret }, \text { flex }}} \\
\dot{Q}_{\text {late discharge }}=\dot{Q}_{\text {dem }} \frac{T_{\text {sup }, \text { ref }}-T_{\text {sup }, \text { flex }}}{T_{\text {sup }, \text { flex }}-T_{\text {ret }, \text { flex }}}
\end{gathered}
$$

\subsection{Very long charge}

When the supply temperature pulse becomes even longer (Figure 14), all three original phases overlap at the same time. This causes the main discharge phase to disappear and a new phase, the neutral phase, to appear. During this neutral phase, there is no change in heat injection between the Reference (dotted line) and Flexibility (full line) case. The effects during the three original phases (charge, discharge, rebound) are cancelling each other out. The same counts for errors in the return temperature estimation, as can be derived in a similar fashion to Equation 34.

\subsection{Computation times}

Table 5 shows a comparison of the time it took to simulate the network for one year with each of the substation models. These simulations were done on a Dell Latitude E7470 device with an Intel ${ }^{\circledR}$ Core $^{T M}$ i7 6600U 2.60 $\mathrm{GHz}$ with 2 cores (4 logical processors) with 16 GB RAM. The simpler the substation model, the shorter the computation time. 

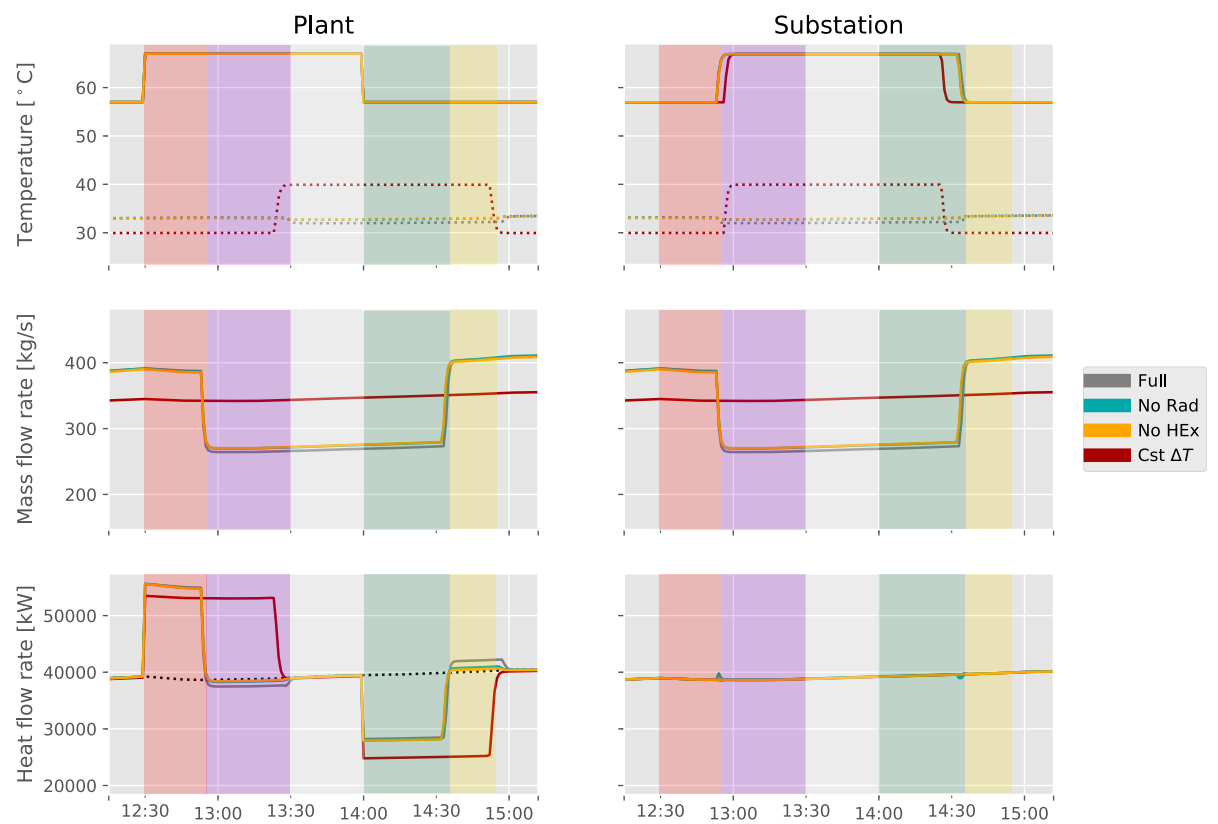

Figure 14: The simulation results of a very long charge. From top to bottom, temperatures, mass flow rates and heat flow rates are shown. On the left side, these results are shown for the plant side of the network, on the right for the substation side.

\section{Discussion}

A first conclusion of this substation model evaluation is that the Cst $\Delta T$ is not a suitable substation model, as produces qualitatively very different results. Even though this model allows linear optimisation of network flexibility as was done in [19, 24] and has the fastest computation time, it does not seem correct to do this.

The main factor that influences network flexibility characterisation is the modelled primary return temperature of the substation. This is the property that must be properly modelled or estimated when considering the substation model. The No Rad model does this by replacing the radiator by a $1 \mathrm{D}$ look- 
Table 5: The computation time of a year simulation for each substation model.

\begin{tabular}{|l|c|}
\hline Substation & Computation time \\
\hline Full & $51.0 \mathrm{~s}$ \\
\hline No Rad & $39.1 \mathrm{~s}$ \\
\hline No HEx & $11.8 \mathrm{~s}$ \\
\hline Cst $\Delta T$ & $1.71 \mathrm{~s}$ \\
\hline
\end{tabular}

up table with the SH heat demand as only input and has the secondary return temperature as output. The No HEx model uses a 2D look-up table that replaces both radiator and heat exchangers. The inputs of this table are the $\mathrm{SH}$ heat demand and the primary supply temperature, while the output is the primary return temperature. The results show that the difference between these two models is very small, meaning the extra assumptions made in the No HEx model are acceptable.

For the charge, main discharge and late discharge phases, the two reduced models work well, yet for the rebound phase and the early discharge phase, it seems that even small deviations ( $\mathrm{such}$ as $0.5^{\circ} \mathrm{C}$ ) in the primary return temperature estimation can lead to large relative errors, though absolute errors may be small.

Assuming that these errors are acceptable, No Rad and No HEx seem interesting to use for network flexibility characterisation of district heating systems. They simplify the substation models, eliminating some components (the radiator and/or the heat exchanger), simplifying and speeding up the problem. Only some limited preprocessing to generate the look-up tables is required. No HEx has the extra advantage of leaving out the heat exchanger, 
while still having the same performance as $N o$ Rad and a shorter computation time. Hence, should the application allow for these minor errors, significant simplifications to the Full model can be made.

Two important assumptions have been made in this research. The first is the aggregation of the district, which can influence the behaviour of the substation as was already mentioned in Section 3.3.1. The second is the assumption that the Full model represents reality. Future research should focus on a similar comparison, yet provide measurement data of a real substation to serve as a reference or a validation of the Full substation model.

\section{Conclusion}

This paper compares different substation models for the specific application of network flexibility characterisation in district heating systems. Network flexibility is created by temporarily increasing the supply temperature to charge the water in the network pipes. To characterise this flexibility an accurate representation of the network behaviour is required. To this end, four different substation models were compared. The first is the most detailed one, modelling the radiator, heat exchangers and a realistic control system in a building substation. The other substation models replace the radiator and/or heat exchanger models with a look-up table. The results show that the assumption of a constant temperature difference across the substation is not accurate. However, it is possible to remove the radiator and heat exchanger models, and replace them by simplified representations describing the return temperatures in the substation as a function of the heat demand and/or the incoming supply temperature. Although it should 
be noted that the accuracy of these models depends on the network flexibility phase. During the charge, main discharge and late discharge phases, the performance is quite well and rather insensitive to errors in the return temperature predictions. However, during the rebound and early discharge phases, the performance is quite sensitive to small errors in the prediction and large relative errors (but small absolute errors) can occur. Should these relative errors be acceptable, the radiator and heat exchanger models can be omitted, making these reduced substation models promising for flexibility characterisation techniques using simulation or optimisation.

\section{Acknowledgements}

The authors gratefully acknowledge EFRO/SALK for funding the research work of Bram van der Heijde and Annelies Vandermeulen through the project 'Towards a Sustainable Energy Supply in Cities', which received the support of the European Union, the European Regional Development Fund ERDF, Flanders Innovation \& Entrepreneurship and the Province of Limburg. The work of Bram van der Heijde and Annelies Vandermeulen is further financed by VITO through a PhD Fellowship. We would also like to thank the members of IBPSA project 1 for their help and useful suggestions. This project is an international project conducted under the umbrella of the International Building Performance Simulation Association (IBPSA). Project 1 will develop and demonstrate a BIM/GIS and Modelica Framework

for building and community energy system design and operation. 


\section{References}

[1] European Commision. An EU Strategy on Heating and Cooling. Technical report, European Commission, 2016.

[2] S. A. Paardekooper, R. F. Lund, B. vad Mathiesen, M. A. C. Ojeda, Petersen U. R., A. Grundahl, D. Lars, J. Dahlbæk, I. A. Kapetanakis, H. Lund, N. Bertelsen, K. Hansen, D. W. Drysdale, and U. Persson. Heat Roadmap Europe : Quantifying the Impact of Low-Carbon Heating and Cooling Roadmaps. Aalborg Universitetsforlag, Copenhagen, Technical Report, 2018.

[3] U. Persson, B. Möller, and S. Werner. Heat Roadmap Europe: Identifying strategic heat synergy regions. Energy Policy, 74(C):663-681, 2014. ISSN 03014215. doi: 10.1016/j.enpol.2014.07.015. URL http: //dx.doi.org/10.1016/j.enpol.2014.07.015.

[4] H. Lund. Renewable heating strategies and their consequences for storage and grid infrastructures comparing a smart grid to a smart energy systems approach. Energy, 2018. ISSN 03605442. doi: 10.1016/j.energy. 2018.03.010.

[5] A. Vandermeulen, B. van der Heijde, and L. Helsen. Controlling District Heating and Cooling Networks to Unlock Flexibility : a Review. Energy, 151:103-115, 2018. doi: https://doi.org/10.1016/j.energy.2018.03.034.

[6] S. Frederiksen and S. Werner. In District Heating and Cooling, chapter 9, pages 365-370. Studentlitteratur, 2014. 
[7] D. Basciotti, F. Judex, O. Pol, and R.-R. Schmidt. Sensible heat storage in district heating networks : a novel control strategy using the network as storage. In Conference proceedings of the 6th international renewable energy storage conference IRES, Berlin, Germany, 2011.

[8] L. Giraud, M. Merabet, R. Baviere, and M. Vallée. Optimal Control of District Heating Systems using Dynamic Simulation and Mixed Integer Linear Programming. In Proceedings of the 12th International Modelica Conference, number March, pages 141-150, Prague, Czech Republic, 2017. doi: 10.3384/ecp17132141. URL http://www.ep.liu.se/ecp/ article . asp? issue $=132\{\%\} 26$ article $=14$.

[9] M. Leśko, W. Bujalski, and K. Futyma. Operational optimization in district heating systems with the use of thermal energy storage. Energy, 165:902-915, 2018. ISSN 03605442. doi: 10.1016/j.energy.2018.09.141.

[10] Z. Li, W. Wu, and M. Shahidehpour. Combined Heat and Power Dispatch Considering Pipeline Energy Storage of District Heating Network. IEEE Transactions on Sustainable Energy, 7(1):12-22, 2016.

[11] W. Gu, J. Wang, S. Lu, Z. Luo, and C. Wu. Optimal operation for integrated energy system considering thermal inertia of district heating network and buildings. Applied Energy, 199:234-246, 2017. ISSN 03062619. doi: 10.1016/j.apenergy.2017.05.004. URL http://dx.doi. org/10.1016/j. apenergy.2017.05.004.

[12] Z. Pan, J. Wu, H. Sun, and M. Abeysekera. Quantification of Operational Flexibility from a Heating Network. Energy Procedia, 145:516- 
521, 2018. ISSN 1876-6102. doi: 10.1016/j.egypro.2018.04.075. URL https://doi.org/10.1016/j.egypro.2018.04.075.

[13] T. Nuytten, B. Claessens, K. Paredis, J. Van Bael, and D. Six. Flexibility of a combined heat and power system with thermal energy storage for district heating. Applied Energy, 104:583-591, 2013. ISSN 03062619. doi: 10.1016/j.apenergy.2012.11.029. URL http://dx.doi. org/10.1016/j.apenergy.2012.11.029.

[14] S. Stinner, K. Huchtemann, and D. Müller. Quantifying the operational flexibility of building energy systems with thermal energy storages. Applied Energy, 181:140-154, nov 2016. ISSN 03062619. doi: 10.1016/j.apenergy.2016.08.055.

[15] R. De Coninck and L. Helsen. Quantification of flexibility in buildings by cost curves - Methodology and application. Applied Energy, 162:653665, jan 2016. ISSN 03062619. doi: 10.1016/j.apenergy.2015.10.114.

[16] G. Reynders. Quantifying the impact of building design on the potential of structural strorage for active demand response in residential buildings. $\mathrm{PhD}$ thesis, KU Leuven, 2015.

[17] G. Reynders, R. Amaral Lopes, A. Marszal-Pomianowska, D. Aelenei, J. Martins, and D. Saelens. Energy flexible buildings: An evaluation of definitions and quantification methodologies applied to thermal storage. Energy and Buildings, 166:372-390, 2018. ISSN 03787788. doi: 10.1016/j.enbuild.2018.02.040. URL https://doi.org/10.1016/ j.enbuild.2018.02.040. 
[18] R. Grønborg Junker, R. Relan, R. Amaral Lopes, G. Reynders, K. Byskov Lindberg, and H. Madsen. Characterizing the Energy Flexibility of Buildings and Districts. Applied Energy, 225(May):175-182, 2018. ISSN 0306-2619. doi: 10.1016/j.apenergy.2018.05.037. URL https://doi.org/10.1016/j.apenergy.2018.05.037.

[19] A. Vandermeulen, G. Reynders, B. van der Heijde, D. Vanhoudt, R. Salenbien, D. Saelens, and L. Helsen. Sources of energy flexibility in district heating networks: building thermal inertia versus thermal energy storage in the network. In Proceedings of Urban Energy Simulations Conference, Glasgow, UK, 2018.

[20] G. Schweiger, P.-O. Larsson, F. Magnusson, P. Lauenburg, and S. Velut. District heating and cooling systems - Framework for Modelica-based simulation and dynamic optimization. Energy, 137:566-578, 2017.

[21] J. Gustafsson, J. Delsing, and J. Van Deventer. Thermodynamic simulation of a detached house with district heating subcentral. 2008 IEEE International Systems Conference Proceedings, SysCon 2008, pages 485492, 2008. doi: 10.1109/SYSTEMS.2008.4519054.

[22] L. Giraud, R. Bavière, C. Paulus, M. Vallée, and J.-F. Robin. Dynamic Modelling, Experimental Validation and Simulation of a Virtual District Heating Network. In Proceedings of ECOS 2015, number June, Pau, France, 2015.

[23] L. Laakkonen, T. Korpela, J. Kaivosoja, M. Vilkko, Y. Majanne, and M. Nurmoranta. Predictive Supply Temperature Optimization of Dis- 
trict Heating Networks Using Delay Distributions. Energy Procedia, 116: 297-309, 2017. ISSN 18766102. doi: 10.1016/j.egypro.2017.05.076. URL http://dx.doi.org/10.1016/j.egypro.2017.05.076.

[24] E. Ikonen, I. Selek, J. Kovacs, M. Neuvonen, Z. Szabo, J. Bene, and J. Peurasaari. Short term optimization of district heating network supply temperatures. ENERGYCON 2014 - IEEE International Energy Conference, pages 996-1003, 2014. ISSN 2164-4322. doi: 10.1109/ENERGYCON.2014.6850547.

[25] D. Basciotti and R.-R. Schmidt. Peak Reduction in District Heating Networks: a Comparison Study and Practical Considerations. 14th International Symposium on District Heating and Cooling, 2014.

[26] H. Kauko, K. H. Kvalsvik, D. Rohde, N. Nord, and A. Utne. Dynamic modeling of local district heating grids with prosumers: A case study for Norway. Energy, 151:261-271, 2018. ISSN 03605442. doi: 10.1016/j. energy.2018.03.033. URL https://doi .org/10.1016/j .energy . 2018. 03.033 .

[27] X. Yang, H. Li, and S. Svendsen. Decentralized substations for low-temperature district heating with no Legionella risk, and low return temperatures. Energy, 110:65-74, 2016. ISSN 03605442. doi: 10.1016/j.energy.2015.12.073. URL http://dx.doi.org/10.1016/j. energy.2015.12.073.

[28] J. Gustafsson, J. Delsing, and J. van Deventer. Improved district heating substation efficiency with a new control strategy. Applied Energy, 87(6): 
1996-2004, 2010. ISSN 03062619. doi: 10.1016/j.apenergy.2009.12.015. URL http://dx .doi .org/10.1016/j . apenergy . 2009.12.015.

[29] I. De Jaeger, A. Vandermeulen, B. van der Heijde, D. Saelens, and L. Helsen. Aggregating Occupant Behaviour for Archetype-based Simulations of the Heat Demand within Residential Districts. submitted to Journal of Building Performance Simulation, 2019.

[30] Bram van der Heijde, Annelies Vandermeulen, Robbe Salenbien, and Lieve Helsen. Integrated Optimal Design and Control of Fourth Generation District Heating Networks with Thermal Energy Storage. Energies, 12(14):2766, 2019. ISSN 1996-1073. doi: 10.3390/en12142766. URL https://www.mdpi.com/1996-1073/12/14/2766.

[31] H. Lund, S. Werner, R. Wiltshire, S. Svendsen, J. E. Thorsen, F. Hvelplund, and B. Vad Mathiesen. 4th Generation District Heating (4GDH) Integrating smart thermal grids into future sustainable energy systems. Energy, 68:1-11, 2014. ISSN 0360-5442. doi: 10.1016/j.energy. 2014.02.089. URL http://dx.doi.org/10.1016/j.energy.2014.02. 089.

[32] F. Haugen. The good gain method for simple experimental tuning of PI controllers. Modeling, Identification and Control, 33(4):141-152, 2012. ISSN 03327353. doi: 10.4173/mic.2012.4.3.

[33] Isoplus. Isoplus product catalogue, 2016.

[34] R. Baetens, R. De Coninck, F. Jorissen, D. Picard, L. Helsen, and D. Saelens. OpenIDEAS - an Open Framework for District Energy 
Simulations. BS2015, 14th Conference of International Building Performance Simulation Association, pages 347-354, 2015.

[35] M. Wetter, M. Fuchs, P. Grozman, L. Helsen, F. Jorissen, M. Lauster, D. Muller, C. Nytsch-geusen, D. Picard, P. Sahlin, and M. Thorade. IEA EBC Annex 60 Modelica Library - an International Collaboration to Develop a Free Open-source Model Library for buildings and and community energy systems. In 14 th Conference of International Building Performance Simulation Association, pages 395-402, Hyderabad, India, 2015.

[36] B. van der Heijde, M. Fuchs, C. Ribas Tugores, G. Schweiger, K. Sartor, D. Basciotti, D. Müller, C. Nytsch-geusen, M. Wetter, and L. Helsen. Dynamic equation-based thermo-hydraulic pipe model for district heating and cooling systems. Energy Conversion and Management, 151 (July):158-169, 2017. ISSN 0196-8904. doi: 10.1016/j.enconman. 2017.08.072. URL http://dx.doi.org/10.1016/j.enconman.2017. 08.072 